\title{
HYDRATION AND MICROSTRUCTURE OF BLENDED CEMENT WITH SODIUM POLYSTYRENE SULFONATE
}

\author{
${ }^{\#}$ WEIFENG LI*, SUHUA MA*, YUEYANG HU*, XIAODONG SHEN**** \\ *College of Materials Science and Engineering, Nanjing Tech University, Nanjing 210009, China \\ **State Key Laboratory of Materials-Oriented Chemical Engineering \\ "\#-mail: yc982@126.com
}

Submitted April 23, 2016; accepted July 18, 2016

\begin{abstract}
Keywords: Sodium polystyrene sulfonate; hydration; microstructure; blended cement
Polystyrene foamed plastic wastes are a kind of environmental pollutant. It could be recycled in cement industry as a chemical agent. In this paper, the effects of sodium polystyrene sulfonate (SPS) on the hydration and microstructure of blended cement were investigated by calorimetry, X-ray diffraction (XRD), scanning electron microscopy (SEM) and mercury intrusion porosimetry (MIP). SPS slightly delayed the hydration of alite and decreased its hydration degree. SPS did not change the phase compositions during hydration. SPS changed the morphology of ettringite (AFt) and decreased the pore volumes and the sizes of pores.
\end{abstract}

\section{INTRODUCTION}

Concrete is a widely used structural material. With the increasing requirements for concrete durability and performance, new types of chemical additives have been developed, including superplasticizers (SPs). Over the past few decades, significant progress has been made in the application of SPs [1-4]. SPs play increasingly important roles in concrete. SPs are adsorbed on cement particles, providing the possibility of a better dispersion of cement particles [5]. SPs include lignosulfonic acids (LSs), melamine formaldehyde sulfonic acids (SMFs), naphthalene formaldehyde sulfonic acids (SNFs) and polycarboxylic acids (PCs) [5, 6-8]. Polycarboxylic acids are the most utilized among SPs. A number of studies have examined the effects of PCs on the hydration, morphology and microstructural development of cements [9-10]. However, the price of PCs is relatively higher, compared with cements. Additionally, a number of byproducts are produced in the production of PCs.

It is well known that polystyrene foamed plastic wastes are a primary source of environmental pollution. Thus, the recycle of polystyrene foamed plastic wastes provides significant social and economic benefits. The benzene ring in the polystyrene molecule has high chemical activity. Polystyrene can be modified into a water-soluble and functional polymer by introducing functional end groups, such as sulfonic acids, carboxylic acids and hydroxyl groups, into the benzene ring [11-12] . El-Hosiny, F.I., et al. [13] investigated the effect of sodium polystyrene sulfonates on the mechanical and physico- chemical properties of blended cementitious pastes. It did not affect the phase composition of the blended cement hydration products. Using microelectrophoresis and UV-absorption techniques, Andersen, P.J., et al. [14] showed that sulfonated polystyrenes had larger negative $\mathrm{ZP}$ values and higher dispersibility, compared with sulfonated naphthalene and sulfonated melamine. Our research found [15] that $0.04 \%$ SPS increased the compressive strengths by $19 \%$ and $8 \%$ at $3 \mathrm{~d}$ and $28 \mathrm{~d}$ respectively, compared to the blank cement.

In this paper, it was investigated systematically on the effects of SPS on the hydration and microstructure development of blended cement. Its aim is to provide a theoretic guide for the recycle of Polystyrene foamed plastic wastes.

\section{EXPERIMENTAL}

\section{Materials}

In this paper, the blended cement was obtained from a cement company in China. The blended cement was made of $55 \%$ Portland cement clinker, $30 \%$ fly ash, 6 $\%$ slag, $5 \%$ limestone and $4 \%$ gypsum. The chemical compositions of Portland cement clinker are shown in Table 1 . SPS was added at $0.01 \%, 0.03 \%, 0.05 \%$, $0.1 \%$ and $0.2 \%$ by weight of the blended cement. And the structure of SPS is shown in Figure 1. The blended cement paste was made of the blended cement and deionized water. The ratio of water to the cement was 0.4 . 
Table 1. Chemical analysis of Portland cement clinker used.

\begin{tabular}{lc}
\hline & Chemical analysis $(\mathrm{g} / 100 \mathrm{~g})$ \\
\hline $\mathrm{CaO}$ & 64.80 \\
$\mathrm{SiO}_{2}$ & 21.77 \\
$\mathrm{Al}_{2} \mathrm{O}_{3}$ & 4.86 \\
$\mathrm{Fe}_{2} \mathrm{O}_{3}$ & 3.61 \\
$\mathrm{MgO}$ & 1.21 \\
$\mathrm{SO}_{3}$ & - \\
$\mathrm{K}_{2} \mathrm{O}$ & - \\
$\mathrm{Na}_{2} \mathrm{O}$ & - \\
$\mathrm{TiO}_{2}$ & - \\
Loss & - \\
\hline
\end{tabular}<smiles>CC(C)(C)CC(c1ccc(S([NH3+])(=O)=O)cc1)C(C)(C)C</smiles>

Figure 1. The molecular structure of SPS.

The SPS was prepared as follows [16]: first, waste polystyrene pellets were rinsed with $1.0 \% \mathrm{NaOH}$ solution and distilled water, and then dried in an oven. After that, $50 \mathrm{~g}$ of concentrated $\mathrm{H}_{2} \mathrm{SO}_{4}(95 \%)$ with $\mathrm{P}_{2} \mathrm{O}_{3}$ catalyst was mixed in a 3-neck flask with a mixer at $40^{\circ} \mathrm{C}$. Then, $10 \mathrm{~g}$ of polystyrene pellets was dissolved in $75 \mathrm{ml}$ of cyclohexane and added to the 3-neck flask and stirred for $30 \mathrm{~min}$. Subsequently, mixing was stopped in the 3 -neck flask for $1 \mathrm{~h}$ at $40^{\circ} \mathrm{C}$. After that, the 3-neck flask was placed in an ice bath, and the SPS and the cyclohexane solution were separated using a separation funnel. The remainder was washed with water several times and neutralized with $\mathrm{NaOH}$. Finally, the sulfonated polystyrene solution was diluted five-fold for the experiments.

Experimental methods

\section{Isothermal calorimetry}

An 8-channel isothermal calorimeter (TAM Air; Thermometric AB, Sweden) was used to measure the hydration heat flow of the blended cement with and without SPS at $20^{\circ} \mathrm{C}$. The hydration experiments were run for $3 \mathrm{~d}$.

\section{$X$-ray powder diffraction}

The phase development was investigated on a $\mathrm{Ri}$ gaku SmartLab 3000 A diffractometer with $\mathrm{CuK} \alpha$ radiation $(\lambda=0.154 \mathrm{~nm})$. The $\mathrm{X}$-ray tube was operated at $35 \mathrm{kV}$ and $30 \mathrm{~mA}$. The optics configuration included a fixed divergence slit $\left(1 / 2^{\circ}\right)$ and a $\mathrm{D} /$ teX Ultra detector. The measurements were collected using $\theta-\theta$ reflection geometry. Data were collected from $10^{\circ}$ to $70^{\circ}$ in continuous mode.

\section{Scanning electron microscopy analysis}

For the morphology investigations, a few pieces of the cements were coated with carbon and examined using a JSM-5900 SEM operated at $30 \mathrm{kV}$.

\section{Mercury intrusion porosimetry analysis}

The porosity and pore size distribution were studied using a Quanta chrome PoreMaster GT60 mercury intrusion porosimeter capable of generating high pressures in the range of 20 psia to 20,000 psia and low pressures in the range of 1.1 psia to 20 psia. The porosimeter can be used to measure pore sizes ranging from $0.0035 \mu \mathrm{m}$ to $400 \mu \mathrm{m}$. The pore radii were calculated according to the Washburn equation, $r=-2 \gamma \cos \theta / \mathrm{P}$, where $r$ is the pore entry radius in which mercury is introduced, $\gamma$ is the surface tension, and $P$ and $\theta$ are the applied pressure and the contact angle of mercury with the solid, respectively.

\section{RESULTS AND DISCUSSION}

\section{Hydration kinetics}

Heat flow can characterize the hydration kinetics of cements. The heat evolution curve of typical Portland cement broadly resembles that of $\mathrm{C}_{3} \mathrm{~S}$ [17]. According to the heat flow curve for typical Portland cement, the hydration reaction is separated into three periods as follows: the (1) early, (2) middle, and (3) late stages of reaction. In the early stage, the initial peak was attributed to exothermic wetting and the formation of an AFt phase. In the middle stage, the second peak was attributed mainly to the hydration of $\mathrm{C}_{3} \mathrm{~S}$. Figure $2 \mathrm{a}$ shows

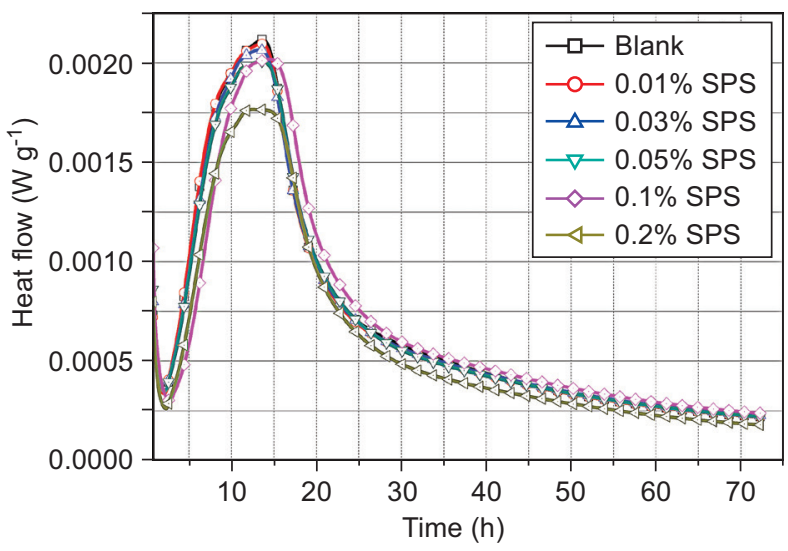

a)

Figure 2. Heat flow curves and cumulative heat curves for cements. 


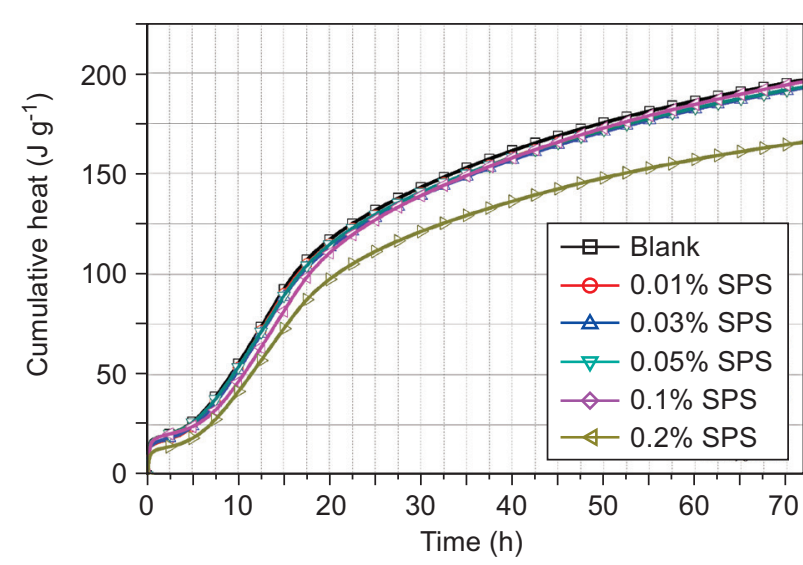

b)

Figure 2. Heat flow curves and cumulative heat curves for cements.

that SPS did not significantly change the hydration kinetics for the blended cement. However, as the SPS dosage increased, the hydration rate of $\mathrm{C}_{3} \mathrm{~S}$ decreased. The second exothermic peak moved slightly to the right for the blended cement with $0.1 \%$ and $0.2 \%$ SPS Setting takes place during an acceleratory period [17]. These results indicated that a large amount of sulfonated polystyrene will delay the hydration of $\mathrm{C}_{3} \mathrm{~S}$ and prolong the setting time.

The cumulative heat was lower for the blended cement with $0.2 \%$ SPS (see Figure $2 b$ ), compared to the other cements. With the ongoing hydration, the cumulative heat difference increased between the blended cement with $0.2 \%$ SPS and the other cements.

\section{Development of hydration products}

To investigate the effect of SPS on the development of hydration products, the hydration of the blended cements with and without SPS was monitored by XRD.

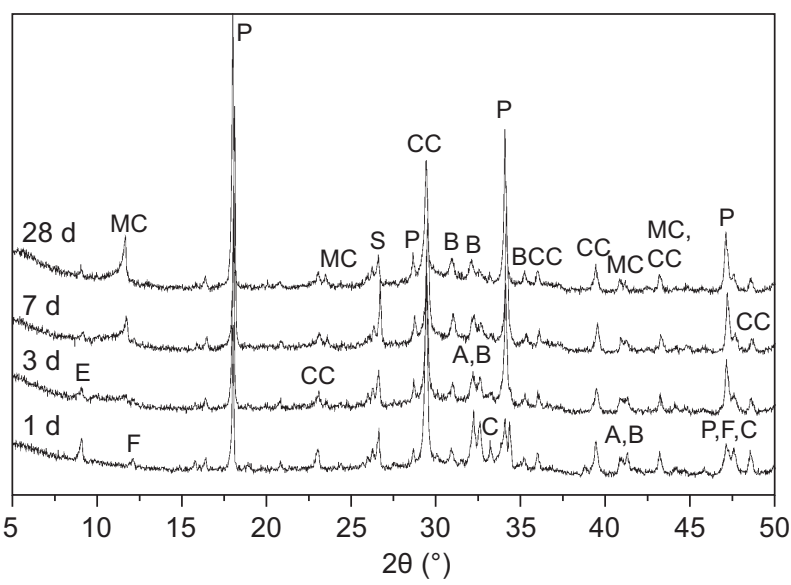

a) blank cement
The XRD patterns are shown in Figure 3 for the blended cements with $0.05 \%$ SPS and without SPS hydrated for different ages. As reported by Copeland L.E., et al. [18], gypsum was no longer detectable after $1 \mathrm{~d}$ (see Figure $3 \mathrm{a}$ ), and the cement phases were consumed at different rates. The ratio of belite to alite steadily increased, and after $28 \mathrm{~d}$, little or no alite, aluminate and ferrite phases were detectable. The calcite and $\mathrm{SiO}_{2}$ were also increasingly less detectable with the ongoing hydration for the blank cement. At $1 \mathrm{~d}$, the principal products were $\mathrm{AFt}$, portlandite and $\mathrm{C}-\mathrm{S}-\mathrm{H}$. $\mathrm{C}-\mathrm{S}-\mathrm{H}$ was not detected due to its poor crystallinity. When the blank cement was hydrated for $7 \mathrm{~d}$, the diffraction peak of monocarbonate appeared and increased with the hydration duration. By contrast, the AFt content gradually decreased.

SPS did not change the assemblage of the phases for the cement pastes at the same hydration ages (Fig. 3b). These observations were similar to those for Na-polystyrene sulfonate reported by El-Hosiny, F.I., et al. [13]. However, SPS affect the formation rate of AFt and monocarbonates (see Figure 4). At the early stage, the AFt content was lower for the blended cement with SPS, compared with the blank cement. The AFt content decreased for all samples with ongoing hydration and disappeared by 7 days. Monosulfoaluminate was not observed in the XRD pattern. At the same time, monocarbonate formed and increased in all samples due to the continuous hydration. The monocarbonate content was also lower for the blended cement with SPS. However, it was difficult to determine the mechanism by which the monocarbonate was formed, i.e., by the reaction of $\mathrm{C}_{3} \mathrm{~A}$ and $\mathrm{CaCO}_{3}$, the main mineral in limestone, and/or by the reaction of $\mathrm{AFt}, \mathrm{C}_{3} \mathrm{~A}$ and $\mathrm{CaCO}_{3}$. It was previously reported [19] that limestone could stabilize AFt and react with the remaining aluminates to form a combination of mono- and hemicarbonates for ordinary Portland cement-fly ash-limestone systems.

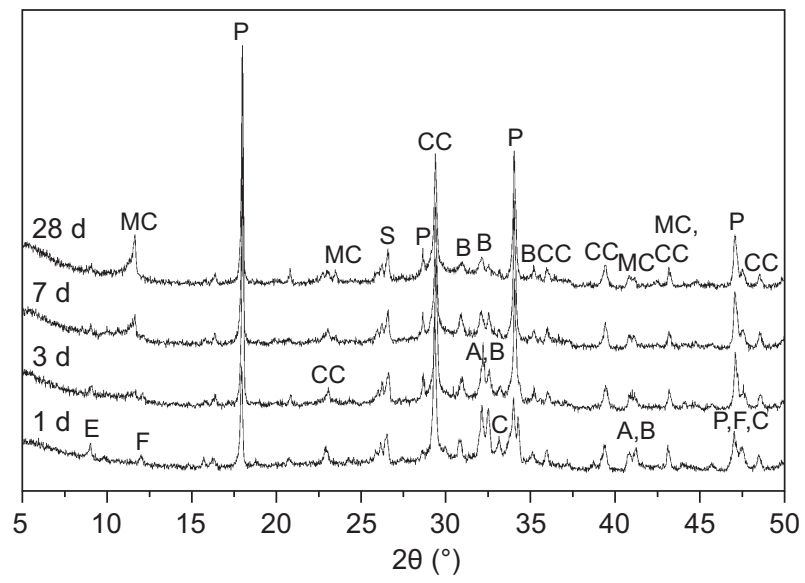

b) blended cement with $0.05 \%$ SPS

Figure 3. The XRD patterns of blank cement hydrated for 1d, 3d, 7d and 28d; a) blank cement, b) blended cement with $0.05 \%$ SPS. 


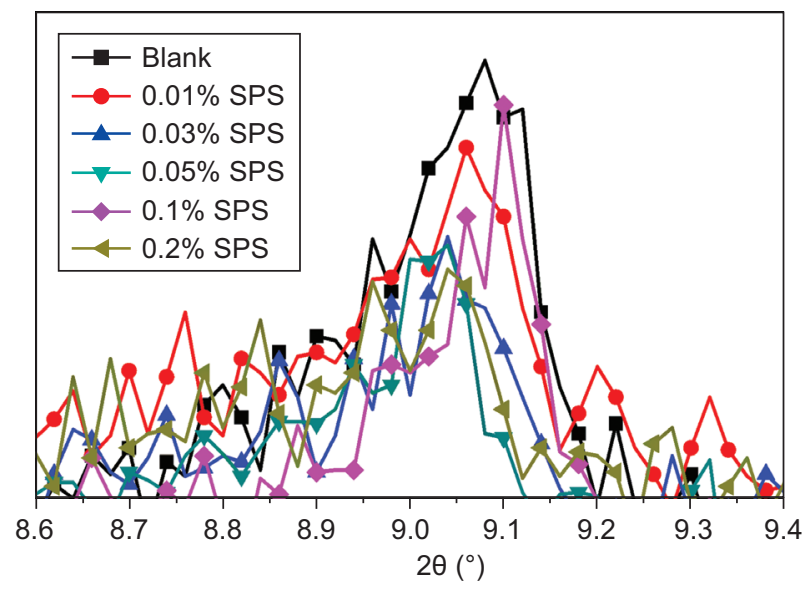

a) Ettringite (1 day)

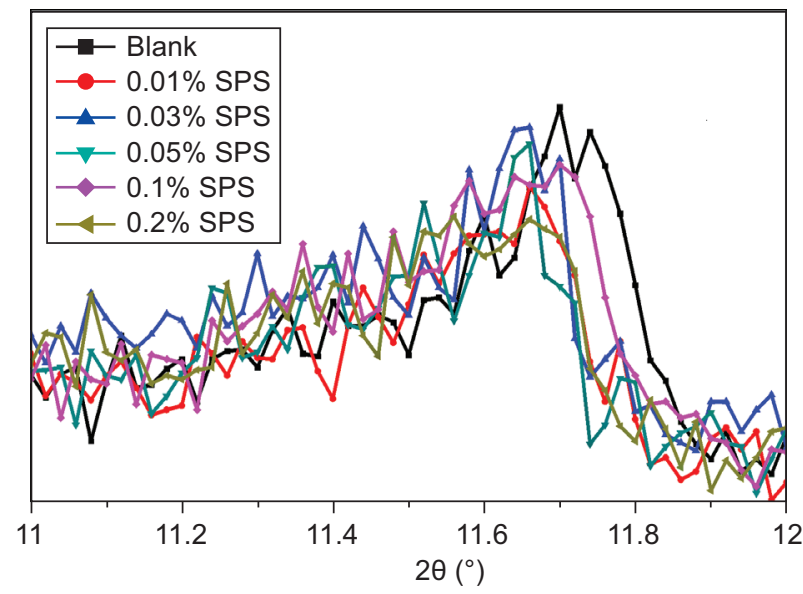

c) Monocarbonate ( 7 days)

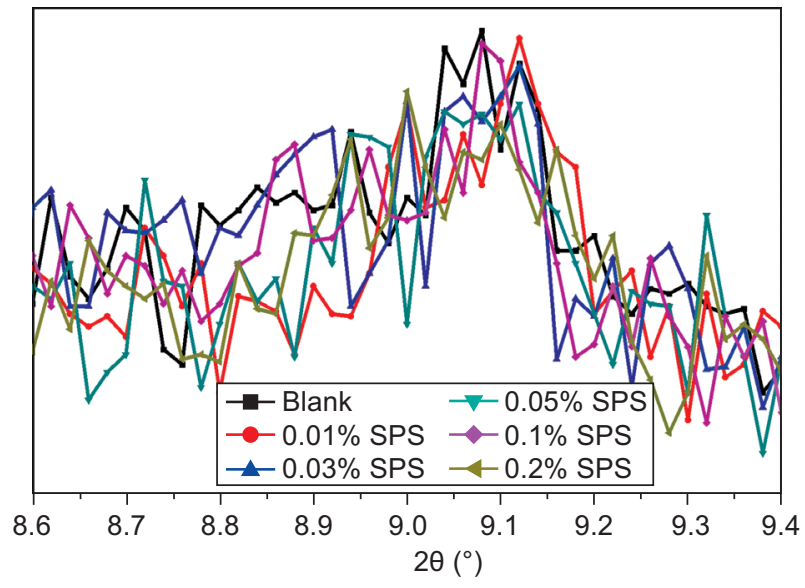

b) Ettringite (3 days)

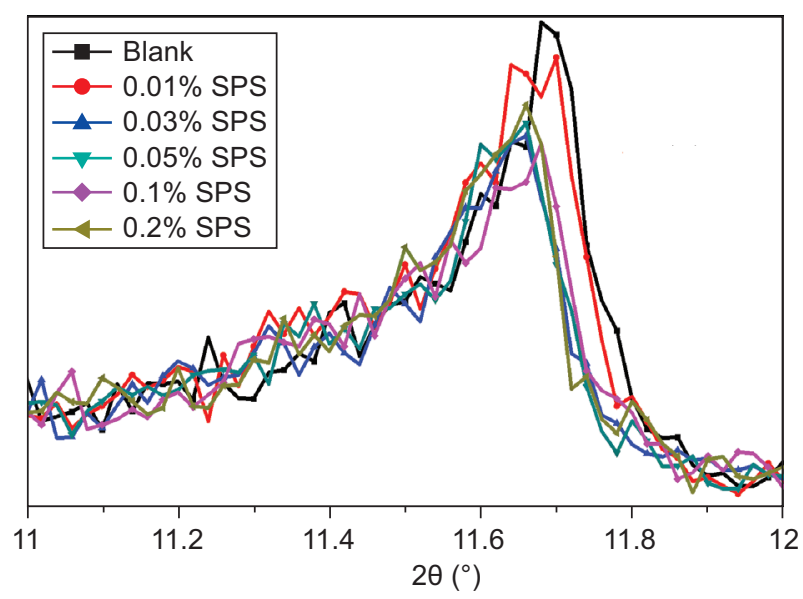

d) Monocarbonate (28 days)

Figure 4. The characteristic peak of ettringite and monocarbonate for cements hydrated for different ages.

\section{Morphology of hydrates}

To investigate the effect of SPS on the morphology of the hydrates, a slice of blended cements without and with $0.05 \%$ SPS hydrated for $1 \mathrm{~d}$ was visualized by SEM. The images are shown in Figure 5. At the early stage,

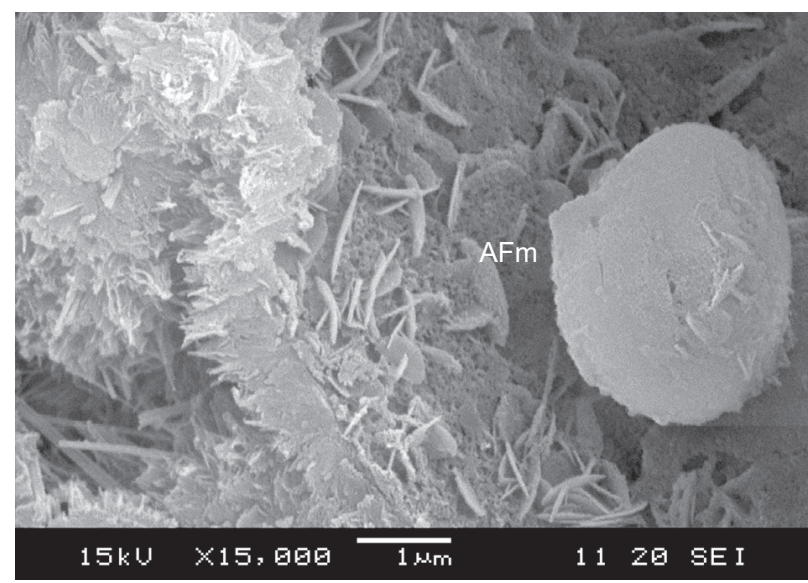

a) blank a large amount of monosulfoaluminate/monocarbonate formed apart from the AFt for the cements without and with $0.05 \%$ SPS (see Figure 5a, b). However, the needle shape of AFt phase in cement paste blended with $0.05 \%$ SPS was more elongated compared with that in reference sample (Blank) (see Figure 5c, d).

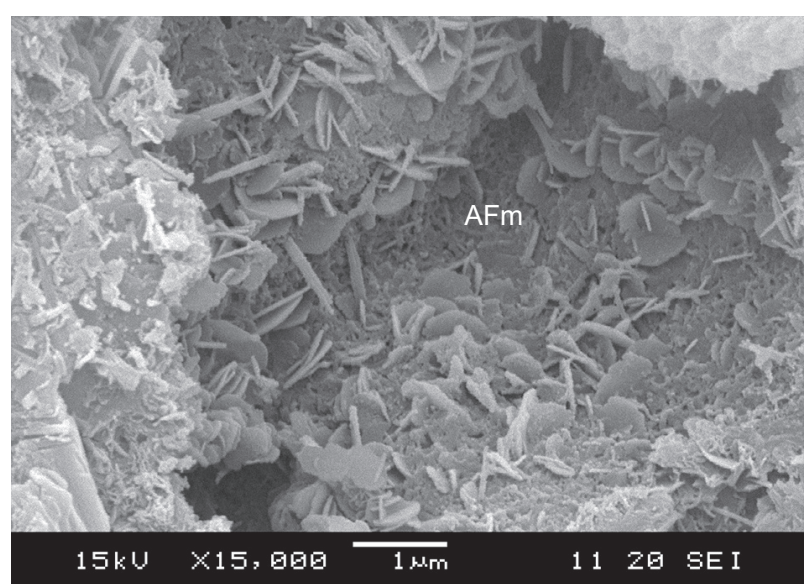

b) $0.05 \% \mathrm{SPS}$

Figure 5. SEM pictures for the blank blended cement and blended cement with $0.05 \%$ SPS hydrated for $1 \mathrm{~d}$. (Continue on next page) 


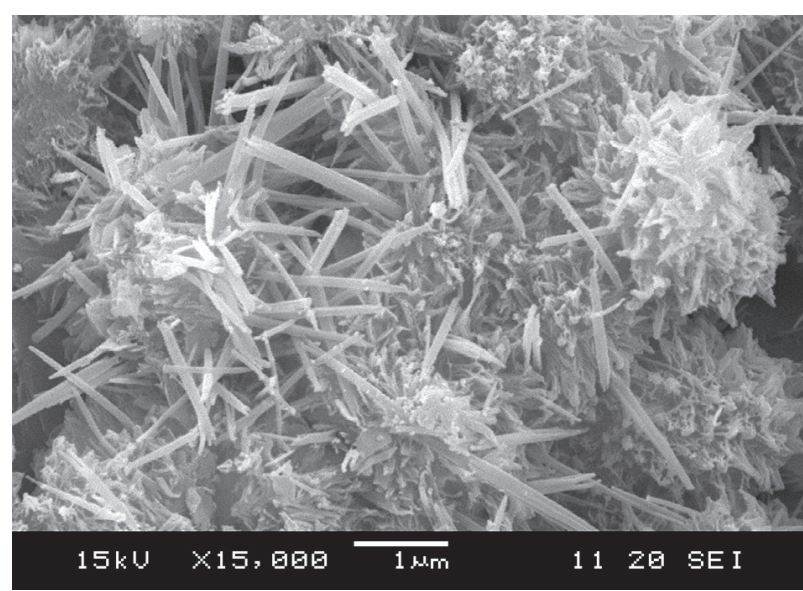

c) blank

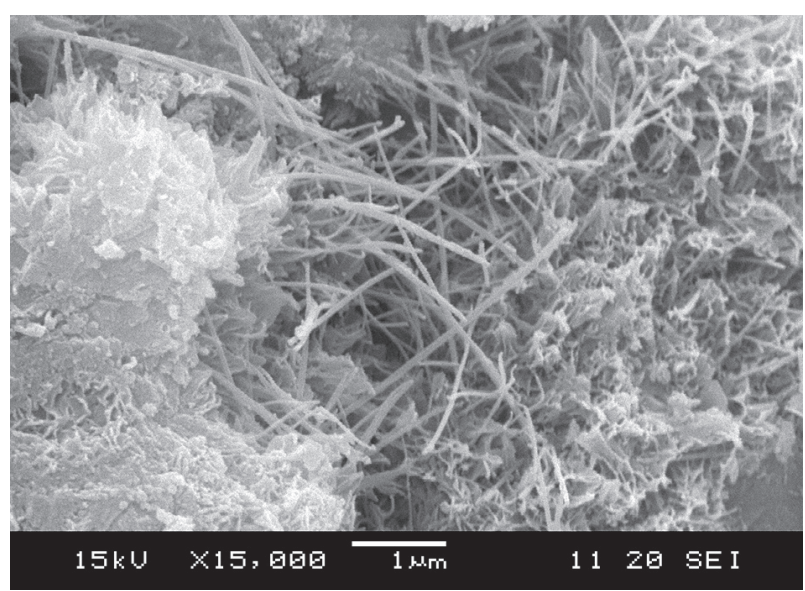

d) $0.05 \% \mathrm{SPS}$

Figure 5. SEM pictures for the blank blended cement and blended cement with $0.05 \%$ SPS hydrated for $1 \mathrm{~d}$.

\section{Pore distribution}

The properties and durability of materials based on cements are dependent on its porous properties. The pore distribution is shown in Figure 6 for all cements hydrated for $3 \mathrm{~d}$ and $28 \mathrm{~d}$. At the early stage (see Figure $6 a)$, the pores were divided into two groups based on

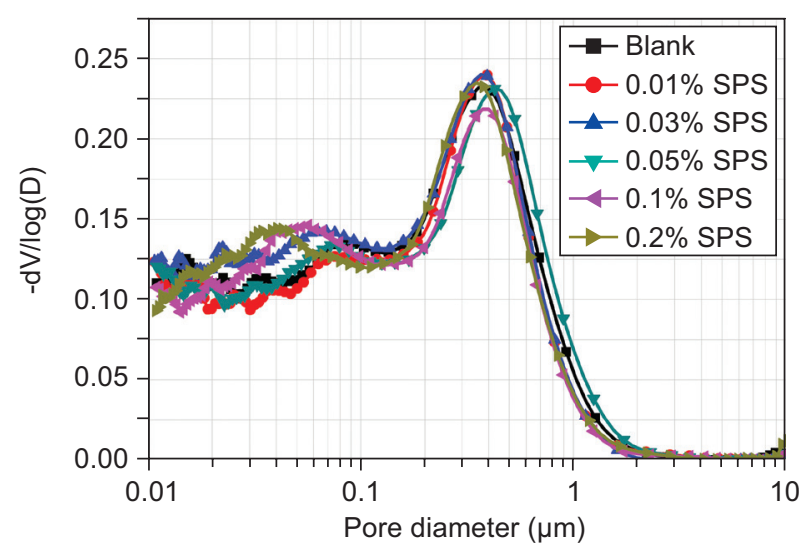

a) $3 \mathrm{~d}$

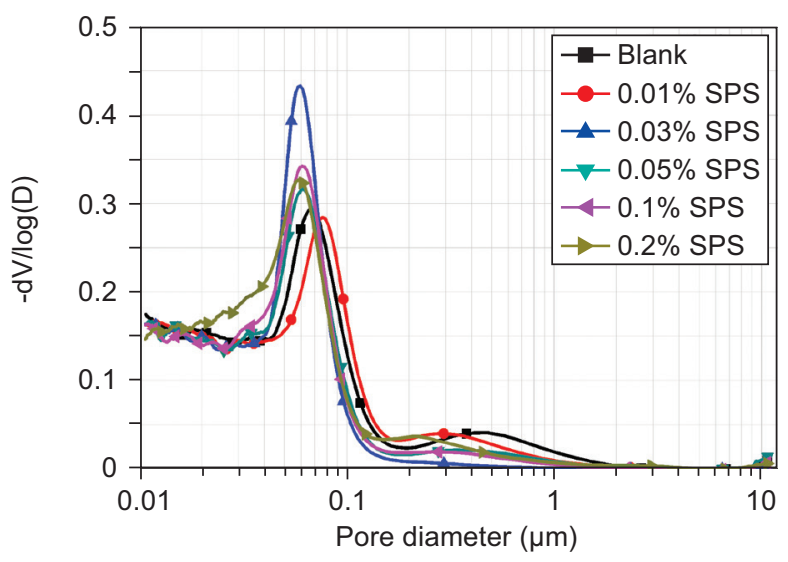

b) $28 \mathrm{~d}$

Figure 6. Pore size distribution for cements hydrated for $3 \mathrm{~d}$ and $28 \mathrm{~d}$. their pore size: from $0.01 \mu \mathrm{m}$ to $0.1 \mu \mathrm{m}$ and from $0.1 \mu \mathrm{m}$ to $2 \mu \mathrm{m}$. The presence of SPS did not change the pore distribution in the range of $0.1 \mu \mathrm{m}$ to $2 \mu \mathrm{m}$. However, SPS decreased the pore sizes of the smaller pores. At $28 \mathrm{~d}$ (see Figure 6b), the pores sizes significantly decreased, compared for the cement pastes hydrated for $3 \mathrm{~d}$. A large distribution of $0.01 \mu \mathrm{m}$ to $0.1 \mu \mathrm{m}$ pores and a small distribution of $0.1 \mu \mathrm{m}$ to $1 \mu \mathrm{m}$ pores were observed. SPS decreased the pores size and the cumulative volumes of pores with $0.1 \mu \mathrm{m}$ to $1 \mu \mathrm{m}$ and. It is well known that the pores in the range of $0.01 \mu \mathrm{m}$ to $2 \mu \mathrm{m}$ affect the strength and permeation of materials based on cements. Hence, the increased strength of cements containing SPS may be related to the decreased pore volumes and sizes.

\section{CONCLUSIONS}

Based on the presented results, large amounts of SPS delayed and decreased the hydration of alite. It did not change the hydration reaction mechanism for the cement clinker-gypsum-fly ash-limestone-slag system. SPS did not change the phase compositions for the blended cement hydrated for $1 \mathrm{~d}, 3 \mathrm{~d}, 7 \mathrm{~d}$ and $28 \mathrm{~d}$ but modifying the morphology of AFt. For this system, monocarbonate formed at $7 \mathrm{~d}$ due to the reaction of $\mathrm{CaCO}_{3}$ from the limestone. SPS decreased the pore sizes and volumes at $3 \mathrm{~d}$ and $28 \mathrm{~d}$.

\section{Acknowledgement}

The authors are grateful for the financial support of the National Natural Science Foundation of China (51202109), the National High Technology Research and Development Program ("863" Program) of China (NO. 2015AA034701), Jiangsu National Synergetic Innovation Center for Advanced Materials (SICAM), 
Top-notch Academic Program Project of Jiangsu Higher Education Institutions(PPZY2015B128), the Priority Academic Program Development of Jiangsu Higher Education Institutions(PAPD) and the State Key Laboratory of Material-Oriented Chemical Engineering (KL14-01). The support by the facilities of the Modern Analysis and Testing Centre at Nanjing Tech University, where the detailed microstructural analyses were performed, are also acknowledged.

\section{REFERENCES}

1. R.Krstulovic, A.Zmikic, P.Dabic. Examination of reaction between the NSF superplasticizer and cement. Cem Concr Res. 1994; 24(5): 948-958.

2. A.Zmikic, R.Krstulovic. Interaction of ionic species in hydrated cement with a superplasticizer admixture, Cem Concr Res. 1994; 24(4): 743-751.

3. M.Yousuf A.Mollah, Padmavathy Palta, Thomas R.Hess, V Rajan K.empati, David L.Cocke. Chemical and physical effects of sodium lignosulfonate superplasticizer on the hydration of portland cement and solidification/stabilization consequences. Cem Concr Res. 1995; 25(3): 671-682.

4. David Bonen, Shondeep L.Sarkar. Superplasticizer adsorption capacity of cement pastes, pore solution composition, and parameters affecting flow loss. Cem Concr Res.1995; 25(7): 1423-1434.

5. S.Chandra, J.Björnström. Influence of cement and superplasticizers type and dosage on the fluidity of cement mortars - Part I. Cem Concr Res. 2002; 32(10):1605-1611.

6. Hui Zhao, Ming Deng, Mingshu Tang. A comparative study on cement hydration and microstructure of cement paste incorporating aminosulfonate-phenol-salicylic acidformaldehyde and aminosulfonate-phenol-formaldehyde polymer. Journal of Thermal Analysis and Calorimetry. 2013; 112(3):1465-1474.

7. Safaa M.A. El-Gamal, Fawzia M.Al-Nowaiser, Asmaa O.Al-Baity. Effect of superplasticizer on the hydration kinetic and mechanical properties of Portland cement pastes. Journal of Advanced Research. 2012; 3(2):119-124.
8. Safaa.M.El Gamal, Heyam M.Bin Salman. Effect of addition of Sikament-R superplasticizer on the hydration characteristics of portland cement pastes. Housing and Building National Research Center. 2012;8 (2):75-80.

9. Fritz Kreppelt, Martin Weibel, Davide Zampini, Michael Romer. Influence of solution chemistry on the hydration of polished clinker surfaces - A study of different types of polycarboxylic acid-based admixtures. Cem Concr Res. 2002; 32(2):187-198.

10. Hiroshi Uchikawa, Daisuke Sawaki, Shunsuke Hanehara. Influence of kind and added timing of organic admixture on the composition, structure and property of fresh cement paste. Cem Concr Res.1995; 25(2):353-364.

11. Yasuhito Inagaki, Shigeo Kiuchi. Converting waste polystyrene into a polymer flocculant for wastewater treatment. Journal of Material Cycles and waste mana-gement. 2001; 3 (1):14-19.

12. Huang Ke,Tang Li-hua, Zhu Zi-bin, Zhang Cheng-fang. Reaction mechanism of styrene monomer recovery from waste polystyrene by supercritical solvents. Polymer Degradation and Stability.2005; 89(2): 312-316

13. F.I.El-Hosiny, E.A.M Gad. Effect of some superplasticizers on the mechanical and physicochemical properties of blended cement pastes. Journal of Applied Polymer Science.1995; 56(2): 153-159.

14. P.J.Andersen, J.M.Gaidis, D.M.Roy. The effects of adsorption of superplasticizers on the surface of cement. Cem Concr Res. 1987; 17 (5):805-813.

15. Weifeng Li, Suhua Ma,Jiaoling Zheng, Xiaodong Shen. Preparation of Cement Grinding Aids with Waste Polystyrene Plastics. Environmental Science \& Technology. 2012; 35 (7):40-42.

16. Hans Vink. A new convenient method for the synthesis of poly (styrenesulfonic acid). Macromolecular chemistry and physics. 1981;182 (1): 279-281.

17. H.F.W.Taylor. Cement chemistry, $2^{\text {nd }}$ edition, published by Thomas Telford Publishing, 1997.

18. L. E. Copeland, D. L. Kantro, G.Verbeck. Chemistry of Hydration of Portland Cement. 4th ISCC, 1960; Vol. I, Session IV, PaperIV-3, 429-465.

19. K. De Weerdt, M. Ben Haha, G. Le Saout, K.O. Kjellsen, H. Justnes, B. Lothenbach. Hydration mechanisms of ternary Portland cements containing limestone powder and fly ash. Cem Concr Res. 2011; 41 (3): 279-291 